\title{
Insegurança, Desperdício e Ajuda Alimentar na Europa do Século XXI'
}

\author{
Cristina Almeida Cunha Filgueiras ${ }^{2}$
}

\section{Resumo}

O artigo examina aspectos sociológicos e políticos da insegurança alimentar e da ajuda em alimentos destinada a milhões de pessoas na Europa. É abordada, inicialmente, a situação de insegurança alimentar associada à pobreza. Em seguida, menciona-se que o grave problema do desperdício de alimentos, o qual tem exigido cada vez mais atenção de governos, organismos internacionais e sociedade, e não pode ser considerado atualmente como causa da falta de acesso à alimentação. Posteriormente, analisa-se o principal programa europeu de ajuda, dando especial atenção ao seu funcionamento na França.

Palavras-chave: Segurança alimentar. Pobreza. Ajuda em alimentos. Desperdício. Política pública.

\section{Insegurança alimentar e pobreza}

Os seres humanos vivem em segurança alimentar quando têm a todo momento o acesso físico e econômico a alimentação suficiente, sadia e nutritiva que lhes permita satisfazer suas necessidades energéticas e suas preferências alimentares para levar uma vida sadia e ativa. Essa noção de segurança alimentar foi difundida a partir do encontro mundial de alimentação realizado em Roma em 1996 (FAO, 1996).

A penúria de gêneros alimentícios, o baixo poder aquisitivo, os problemas de distribuição e a má utilização dos alimentos são fatores que impedem a segurança alimentar. Em 2014, a nona parte da população mundial estava em situação de subalimentaçáo crônica. O problema atinge com maior intensidade

I O artigo é resultado de projeto de pesquisa desenvolvido com os apoios da Coordenação de Aperfeiçoamento de Pessoal de Nivel Superior (CAPES)/Ministério da Educação, da Pontifícia Universidade Católica de Minas Gerais (PUC-Minas) e do Centre Max Weber/Université Lyon 2.

2 Doutora em Sociologia (EHESS), docente do Programa de Pós-graduação em Ciências Sociais da Pontifícia Universidade Católica de Minas Gerais (Pucminas). 
os países pobres; porém, no conjunto dos países desenvolvidos é de cerca de 5\% a taxa de prevalência de subalimentação (FAO, 2014).

A principal causa da subalimentação políticos alertaram para o surgimento da "nova pobreza" e estudiosos assinalaram consequências negativas desse processo sobre a coesão social (CASTEL, 1998). Segundo as estatísticas oficiais, em 2010, 23,4\% da populaçáo da União Europeia (UE) se encontravam em risco de pobreza ou exclusão social (ANTUOFERMO; DI MEGLIO, 2012, p. 1) $)^{3}$. Na França, país que será destacado neste artigo, encontrava-se em situação de pobreza 13\% da população, isto é, cerca de oito milhóes de pessoas. $\mathrm{O}$ fato de uma pessoa viver com renda considerada abaixo da linha de pobreza é um forte indicador de que ela pessoa pode estar em insegurança alimentar (CONSEIL NACIONAL DE L'ALIMENTATION, 2012). Não surpreende, portanto, que nesse contexto existam açóes públicas e privadas de socorro às pessoas necessitadas.

A ajuda alimentar é presença constante na história da na Europa ocidental é a pobreza. Desde os anos 1980, atores sociais, econômicos e França. Desde a metade do século XIX, praticamente a cada 30 anos, em períodos de dificuldades econômicas e de pobreza, ocorreu o ressurgimento desse tipo de ajuda (LEGROS, [s. d.]). Foi o que aconteceu nos anos 1850-1870, nos anos seguintes à Primeira Guerra Mundial, nos anos 1930 e nos anos 1950 . Também em épocas de crescimento da economia a ajuda esteve presente no país, como ocorreu entre 1960-1975, quando ela estava focalizada nas pessoas idosas com escassos recursos.

As relaçóes entre alimentação e pobreza estão inscritas em ciclos econômicos de longa duraçáo, sendo equivocada a ideia de que a ajuda alimentar existiria apenas para enfrentar situaçóes isoladas ou conjunturais. Ao contrário, nos últimos 30 anos a ajuda está estreitamente relacionada na França a um patamar estável de pobreza, composto principalmente por famílias monoparentais, famílias com mais de dois filhos, pessoas idosas, desempregados e trabalhadores pobres.

Dificuldades relacionadas ao acesso à alimentação permanecem, pois, no centro da pobreza, apesar da situaçáo de abundância em que vive a maior

3 Segundo o indicador utilizado pela UE, estão abaixo da linha de pobreza aquelas pessoas com renda inferior a 60\% da mediana em cada país (ANTUOFERMO; DI MEGLIO, 20I2). 
parte da população francesa. As principais organizaçóes sociais envolvidas estimaram terem beneficiado quase quatro milhóes de pessoas em 2013. Acreditam, porém, ser esse número inferior ao de pessoas que enfrentam dificuldades para se alimentar em razão de restriçóes financeiras, pois nem todos que precisam recorrem à ajuda. (OBSERVATOIRE NATIONAL DE LA PAUVRETE ET DE L'EXCLUSION SOCIALE, 2015; BADIA et al., 2014). Um levantamento realizado pela agência de estatística da UE constatou, em 2012, que 8,2\% dos franceses náo podiam financiar uma refeição com proteínas animais (ou seu equivalente vegetal) a cada dois dias. Além disso, foi revelado que $9 \%$ dos beneficiários de programas sociais de renda mínima recorriam à ajuda em alimentos oferecida por associaçôes caritativas. Desequilíbrios também foram detectados em pesquisas com pessoas de baixa renda que náo estão em situação de insegurança alimentar quanto à quantidade de alimentos, porém consomem raramente frutas, legumes, peixes e carnes e, por outro lado, consomem importante quantidade de carboidratos e açúcar (DARMON et al., 2010, p. 5).

\section{Desperdício de alimentos e ajuda}

A desigualdade com relação à segurança alimentar no continente europeu ocorre em países que são grandes produtores de alimentos e onde é elevado o desperdício. No mundo, um terço da produção de alimentos destinada ao consumo humano é desperdiçada a cada ano por problemas em algum dos elos da cadeia entre a produçáo e o consumo (FAO, 2014). O cálculo para a UE é de 89 milhóes de toneladas desperdiçadas anualmente (HIGH, 2014).

O paradoxo da coabitação de grande produção de alimentos, insegurança alimentar e desperdício, assim com as consequências ambientais causadas por este, têm chamado cada vez mais a atenção de governos e sociedades. Não há dúvida de que os alimentos desperdiçados poderiam ter alimentado a milhóes de pessoas; não existe, todavia, relação causal entre desperdício e insegurança alimentar. $\mathrm{Na}$ atualidade, em grande parte dos países do mundo e em especial nos países ricos, a insegurança alimentar náo decorre da escassez de alimentos ou do desperdício. Nessa perspectiva, um aumento da produção não é o que faz falta para permitir às pessoas em situação de pobreza nos países europeus o acesso à alimentação regular e nutritiva. 
Segundo Jean Ziegler (2013), encarregado da relatoria do direito à alimentação da ONU de 2000 a 2008, a destruição massiva de vidas nos países pobres em decorrência da fome, assim como a subalimentação e as carências das pessoas pobres nos países desenvolvidos, têm conexáo com a atuação de grandes grupos econômicos no setor agrícola, a formação dos preços e a especulação com alimentos e terras no mercado financeiro. A situaçáo agravou-se após 2011, quando capitais financeiros migraram para o mercado de matérias-primas, notadamente de alimentos, provocando a elevação dos preços. A alta dos preços prejudicou, ademais, os programas de ajuda alimentar dos países do hemisfério Norte para os do Sul e os programas de ajuda alimentar internos aos países ricos.

Segundo Montagut e Gascón (2014), a culpa do desperdício não pode ser atribuída exclusivamente ao comércio varejista, à restauração e aos consumidores. É preciso reconhecer a responsabilidade do modelo agroindustrial, caracterizado pela promoção do monocultivo, desregulação dos mercados, a lógica de aumento de produtividade e a dissociação entre objetivos econômicos, sociais e ambientais. Além disso, o modelo agroalimentar industrial, com uso intensivo de tecnologia e inovaçóes para aumento contínuo de produtividade, está associado ao desperdício de recursos agrários, solos férteis, água e energia.

$\mathrm{Na}$ Europa, a superprodução agrícola e o desperdício estão relacionados às políticas adotadas e à busca de competitividade internacional. Com frequência, por razóes econômicas, é destruída parte da produção de alimentos, considerada excedente e retirada dos mercados para evitar queda de preços. Nesse contexto, as políticas públicas têm papel ativo no desperdício de alimentos, entre outras razóes porque parte dos produtores agrícolas recebe subsídios.

Em 2014, em decisão relacionada à criação de um fundo para financiar a ajuda alimentar, o Parlamento Europeu reconheceu que a situação de privaçáo de alimentos no continente coexiste com o desperdício. Ademais, a instituição viu no incentivo à doação de excedentes uma das possibilidades de luta contra tal situação:

A grave privação alimentar na União coexiste com um significativo desperdício de alimentos. A este respeito, o Fundo deverá facilitar as doações alimentares, sempre que necessário. No entanto, esta vertente não prejudica a necessidade de remover os obstáculos existentes, a fim de incentivar as doações dos alimentos em excesso para efeitos de luta contra a privação alimentar. (PARLAMENTO EUROPEU, 2014, p. 72-71, destaque nosso). 
Não há nessa proposta de doação de excedentes nenhuma novidade. Como se mostrará na próxima seção, desde 1987 a doação de "alimentos sobrantes" para associaçóes caritativas é a principal estratégia adotada pela UE com relação ao problema da insegurança alimentar. A novidade é a inclusão do problema do desperdício com destaque nas agendas econômica e política dos governos comunitário e estados membros.

Uma vez mais um exemplo francês é útil para esclarecer o contexto europeu atual e os desafios relativos colocados pelo problema do desperdício de alimentos e seus impacto no meio ambiente. Em maio de 2015 foi apresentado ao primeiro ministro um relatório sobre o problema no país, no qual foram apontadas medidas de regulação e açóes que o poder público poderia adotar para enfrentá-lo (GAROT, 2015). Uma das propostas, posteriormente transformada em projeto de lei, provocou reaçóes das associaçóes de ajuda alimentar. A proposta consiste em impedir as empresas de distribuição (supermercados) de produzirem grande quantidade de lixo com os alimentos que descartam e em obrigá-las a reciclar. As empresas são estimuladas a fazer parcerias com associaçóes a quem doaráo os alimentos não vendidos, para sua distribuição aos necessitados. É certo que o projeto de lei tomou em consideração as denúncias, que vinham sendo realizadas há décadas pelas associaçóes caritativas, de que as empresas preferiam destruir alimentos a doá-los. As associaçóes, por um lado, celebram o que acreditam ser um avanço na consciência social com relação ao desperdício de alimentos; por outro, temem que as empresas doadoras descarreguem grandes volumes de doaçóes que as entidades náo teriam capacidade para distribuir. E, ainda, apontam questóes de ordem moral nesse tipo de gestão do desperdício e na forma de doar alimentos às pessoas. ${ }^{4}$

A discussão sobre as formas de enfrentamento do desperdício de alimentos na Europa, ainda que esteja mais centrada em questóes econômicas e ambientais, coloca também em cena a situação social e, com ela, as políticas sociais e o papel das organizaçóes da sociedade civil que atuam na ajuda em alimentos.

4 Outra crítica ao projeto de lei refere-se a não estar nele satisfatoriamente estabelecido o papel do poder público quanto ao controle do cumprimento da legislação. Além disso, é visto como incoerente que cadeias de supermercados, responsáveis por grande quantidade de desperdicio em razão de suas políticas de estoque e logística, usufruam de reduções de impostos quando doam às associações caritativas os excessos que jogariam fora e, além disso, construam uma imagem de empresas com compromisso social. 


\section{A ajuda alimentar na União Europeia}

A pobreza e as reaçóes sociais que ela provoca são partes essenciais da história da Europa. Os historiadores assinalam que a visão sobre a pobreza oscila, segundo a época, entre considerá-la como situação decorrente do comportamento individual ou como fruto do funcionamento da sociedade (SASSIER, 1990). Variam, também, o limite de tolerância coletiva diante da redução de pessoas à sobrevivência física, assim como os tipos de obrigação social, política e econômica frente aos pobres e, em particular, aqueles que não possuem sequer os recursos para se alimentar a cada dia (DELAVIGNE; MONTAIGNE, 2008).

A questão "deve-se alimentar os pobres?" é presença recorrente nas principais obras de economia desde o século XVI (CLEMENT, 2008). Na prática política, as críticas ao princípio da caridade levaram a combinar pão e trabalho, aliando medidas sociais e disciplinares, como ocorre na organização do socorro aos pobres nas workhouses. No nascimento da sociedade industrial, a experiência de alguns condados ingleses de substituir a distribuição de alimentos pelo subsídio ao preço dos cereais fracassou e foi suprimida pelo liberalismo em 1834 (POLANYI, 1980). No contexto geral da Europa moderna, os problemas da privação e da necessidade de socorro com alimentos se manifestaram cada vez mais associados à pobreza dos trabalhadores e ao desemprego. $\mathrm{Na}$ atualidade, as críticas ao socorro público, formuladas por variadas vozes desde outras etapas históricas, continuam sendo expressas. Enquanto alguns observam nessa ajuda o desestímulo ao trabalho e o favorecimento à acomodação, outros denunciam um tratamento degradante aos pobres frente ao direito legítimo à alimentação.

Durante o século XX a construçáo do Estado providência com caráter redistributivo criou expectativas de que, contrariamente ao passado, as necessidades vividas pelos pobres não seriam mais abordadas com atos de caridade individual, por instituiçóes filantrópicas ou por intervençóes públicas desconectadas de um sistema amplo de proteçáo social. No entanto, contrariamente às expectativas, às vésperas do século XXI o socorro em alimentos voltou a ganhar importância.

No caso da França, a ajuda alimentar está longe de ocupar um lugar marginal. Desde meados dos anos 1980 ela se renovou no país, promovida por 
organizaçóes sociais apoiadas no trabalho voluntário, que vieram suprir a escassa presença do poder público e sua incapacidade em enfrentar o ressurgimento da grande pobreza e a instalação do desemprego de longa duração. Em 1984, em conjuntura de elevado desemprego e reaparecimento da miséria, surgiram as primeiras experiências inspiradas nos bancos de alimentos dos Estados Unidos (CONSEIL NACIONAL DE L'ALIMENTATION, 2012). No inverno particularmente rigoroso de 1986-1987, uma grande quantidade de pessoas precisou ser socorrida com abrigo e alimentação; no entanto, as entidades de caráter humanitário e de solidariedade, que foram as mais atuantes, contavam com recursos insuficientes para enfrentar a situação. Nesse contexto, essas entidades se mobilizaram para pressionar os poderes públicos dentro e fora do país. Foi assim que associaçóes francesas, apoiadas por setores políticos, desempenharam papel fundamental nas reivindicaçóes que levaram a Comissão Europeia a criar, em dezembro de 1987, o Programa Europeu de Ajuda a pessoas carentes (PEAD).

O PEAD, que existiu até 2013 como parte integrante da Política Agrícola Comum (PAC), consistiu inicialmente em liberação de parte dos estoques reguladores de alimentos aos governos dos países interessados, para entrega a associações caritativas previamente habilitadas (EUROPEAN COMMISSION, [s. d.]). Os estoques - de trigo, arroz, óleo, leite em pó, manteiga, carne, entre outros ${ }^{5}$ - eram formados em períodos de superprodução com a finalidade de assegurar preços e competitividade no mercado. Em pouco tempo, o programa tornou-se uma das mais importantes fontes de abastecimento para as organizaçóes de ação solidária em contato direto com as populaçóes necessitadas no continente. Aumentaram progressivamente o orçamento, o volume de alimentos distribuídos e o número de pessoas atendidas. $\mathrm{O}$ orçamento, de aproximadamente 100 milhóes de euros em 1987 (EUROPEAN COMMISSION, [s. d.]) alcançou 496 milhóes de euros em 2009 (COUR DES COMPTES, 2009). Contudo, o aumento do gasto não acompanhou o crescimento da demanda por ajuda, provocada pela elevação na pobreza nos países já participantes e pela entrada, após 2004, de outros países na UE.

50 uso dos estoques de frutas, legume e peixes se revelou complexo desde o inicio, em razão das dificuldades enfrentadas pelas organizações de produtores e associações caritativas para gestão dos estoques, embalagem. transporte e distribuição. Por isso, o volume de retiradas foi menor (EUROPEAN COMMISSION, [s. d.]s.d.). 
A divisão de recursos do PEAD entre os estados membros se baseava em dados demográficos e na taxa de risco de pobreza. Em 2009, para uma população de 493 milhôes de habitantes, estimava-se que 80 milhóes estavam nessa condição de risco e 43 milhóes em insegurança alimentar (COUR DES COMPTES, 2009). Cerca de 18 milhóes de pessoas eram, entáo, atendidas pelo programa. O número de países que recebeu recursos variou ao longo dos anos, não apenas porque novos países passaram a integrar o bloco. No período 1993-2012, por exemplo, ele aumentou de dez para 20 países. O Reino Unido participou até 1998 e a Dinamarca até 2004. Outros países não se interessaram em receber recursos do programa. São eles: Alemanha, Áustria, Holanda, Suécia e Chipre (Quadro 9.1).

Em razão do desaparecimento de alguns estoques de alimentos e da limitaçáo de outros, a UE passou a entregar recursos financeiros que permitisse a cada país comprar no mercado alguns produtos a serem entregues às associaçóes habilitadas. O PEAD foi, aos poucos, deixando de se justificar como integrante da política de regulação dos mercados agrícolas e passando a exigir uma justificativa política. Tornou-se necessário afirmar abertamente tratar-se de intervenção de caráter econômico e social para permitir o acesso a um bem primário: a alimentação (INSPECTION GÉNÉRALE DES AFFAIRES SOCIALES, 2008). Não havia, porém, consenso entre os países quanto à necessidade de um programa de ajuda alimentar e menos quanto a financiá-lo com recursos da política agrícola comum. Estados-membros críticos ao programa questionaram na Comissáo Europeia a sua manutenção. Posteriormente, Suécia e Alemanha apresentaram um recurso ao tribunal europeu contra a alocaçáo de recursos para compra de alimentos, argumentando que o programa havia se desviado de seu propósito.

O governo alemão não se opunha ao PEAD se esse utilizasse apenas os estoques agrícolas reguladores e considerava que o programa estava conectado à política agrícola somente porque permitia dar destino aos estoques de regulação. Além disto, defendia que a ajuda alimentar, por tratar-se de política social, não era competência da UE e sim do governo de cada estado membro. Cabe mencionar que na Alemanha não existe ajuda alimentar do poder público às pessoas carentes, sendo esta realizada por associaçôes caritativas com recursos da arrecadaçáo de imposto local destinada às organizaçóes religiosas. 
Quadro I - Países que receberam recursos do PEAD - 1993-20I2

$\stackrel{\Delta}{N}$
1
$\stackrel{D}{\infty}$

\begin{tabular}{|c|c|c|c|c|c|c|c|c|c|c|c|c|c|c|c|c|c|c|c|c|}
\hline $\begin{array}{l}\text { País e ano de entrada } \\
\text { na UE* }\end{array}$ & 1993 & 1994 & 1995 & 1996 & 1997 & 1998 & 1999 & 2000 & 2001 & 2002 & 2003 & 2004 & 2005 & 2006 & 2007 & 2008 & 2009 & 2010 & 2011 & 2012 \\
\hline \multicolumn{21}{|l|}{ Alemanha - I957 } \\
\hline \multicolumn{21}{|l|}{ Áustria - 1975} \\
\hline \multicolumn{21}{|l|}{ Bélgica - 1957} \\
\hline \multicolumn{21}{|l|}{ Bulgária - 2007} \\
\hline \multicolumn{21}{|l|}{ Chipre - 2004} \\
\hline \multicolumn{21}{|l|}{ Dinamarca-1973 } \\
\hline \multicolumn{21}{|l|}{ Estônia - 2004} \\
\hline \multicolumn{21}{|l|}{ Eslovênia - 2004} \\
\hline \multicolumn{21}{|l|}{ Eslováquia-2004 } \\
\hline \multicolumn{21}{|l|}{ Espanha - 1986} \\
\hline \multicolumn{21}{|l|}{ Finlândia -1995 } \\
\hline \multicolumn{21}{|l|}{ França - 1957} \\
\hline \multicolumn{21}{|l|}{ Grécia - 1981 } \\
\hline \multicolumn{21}{|l|}{ Holanda - 1957} \\
\hline \multicolumn{21}{|l|}{ Hungria - 2004} \\
\hline \multicolumn{21}{|l|}{ Irlanda- 1973} \\
\hline \multicolumn{21}{|l|}{ Itália - 1957} \\
\hline \multicolumn{21}{|l|}{ Letônia - 2004} \\
\hline \multicolumn{21}{|l|}{ Lituânia- 2004} \\
\hline \multicolumn{21}{|l|}{ Luxemburgo - 1957} \\
\hline \multicolumn{21}{|l|}{ Malta- 2004} \\
\hline \multicolumn{21}{|l|}{ Polônia - 2004} \\
\hline \multicolumn{21}{|l|}{ Portugal- 1986} \\
\hline \multicolumn{21}{|l|}{ R. Unido - 1973} \\
\hline \multicolumn{21}{|l|}{ Rep. Checa 2004} \\
\hline Romênia - 2007 & & & & & & & & & & & & & & & & & & & & \\
\hline Suécia - 1975 & & & & & & & & & & & & & & & & & & & & \\
\hline
\end{tabular}

* A Croácia passou a integrar a UE em 2013.

Fonte: Adaptado de Cour des Comptes (2009, p. 10) e de European Commission ([s. d.]). 
O que estava em pauta no recurso apresentado ao tribunal europeu, portanto, não era somente a relação entre PEAD e política agrícola, mas também um questionamento à opçáo pela distribuiçáo de alimentos, tanto com participação direta do poder público quanto via financiamento. Em 2011, o tribunal decidiu em favor da demanda apresentada por Alemanha e Suécia, deixando o programa sem base jurídica para continuar no formato em que vinha sendo executado. $\mathrm{O}$ questionamento à ajuda alimentar levou a um impasse jurídico, político e social no qual estava manifesto o conflito entre subsidiariedade e solidariedade (CHAMBON, 2011), opondo duas visóes sobre o papel da UE com relação às questóes sociais. Um grupo de governos, alinhados à primeira perspectiva, considera que a ajuda alimentar náo é parte da política agrícola, pois se trata de política social, cabendo a cada estado-membro financiar e decidir sobre objetivos, características e alcance dos programas sociais. Por sua vez, outros países viam no PEAD uma forma de solidariedade ou simplesmente um modo de financiar com recursos europeus as açóes de ajuda em alimentos.

O bloqueio deu origem à intensa mobilizaçáo de associaçôes e governos interessados na manutençáo do financiamento. As associaçóes europeias se empenharam na defesa do programa (JONET, 2012). As entidades francesas mobilizaram apoios no país e também externamente junto à sociedade civil em países vizinhos, inclusive na Alemanha (BANQUES ALIMENTAIRES, RESTOS DU COEUR... [s. d.]). Ao governo da França interessava que o programa fosse tornado perene e permanecesse estrategicamente dentro da política agrícola comum, cujas despesas são de caráter obrigatório no orçamento da UE.

Diante do impasse criado, o Parlamento Europeu decidiu, em novembro de 2011, pela prorrogação do programa até 2013, porém com menor financiamento. A decisáo foi fruto de um acordo político obtido após intensas negociaçóes lideradas pelos governos da França e da Alemanha.

Como mencionado, desde os anos 1980 a ajuda alimentar se estendeu consideravelmente na França, comprovando que, apesar da abundância em que vive a maior parte da população, as dificuldades de alimentação permanecem no centro da questáo da pobreza. Desde a criação do programa europeu, o país esteve entre os que receberam anualmente maior volume de recursos. 
Em nenhum ano a fatia do orçamento que lhe foi destinada foi inferior a $15 \%$ (CONSEIL NACIONAL DE L'ALIMENTATION, 2012, p. 35), tendo chegado a 24\% em 2003 e 2004 (INSPECTION GÉNÉRALE DES AFFAIRES SOCIALES, 2014, p. 70). Portanto, em pleno impasse quanto à manutenção do programa, a França se mantinha entre os principais beneficiários (Tabela 9.1).

Tabela I - Distribuição do orçamento do PEAD entre países da União Europeia em 2011

\begin{tabular}{lcc}
\hline País & Orçamento destinado (em euros) & $\%$ \\
\hline Itália & 100.649 .380 & 20,8 \\
Polônia & 75.320 .186 & 15,6 \\
Espanha & 74.731 .353 & 15,5 \\
França & 72.741 .972 & 15,1 \\
Romênia & 49.578 .143 & 10,3 \\
Outros 15 países & 373.021 .034 & 67,0 \\
Total & 483.316 .137 & 100,0 \\
\hline
\end{tabular}

Fonte: Adaptada de Conseil National de l'Alimentation (2012, p. 34).

Várias razóes explicam o fato de a França receber parte significativa dos recursos da ajuda alimentar. Destacam-se o tamanho da populaçáo, a taxa de pobreza e a estrutura da ajuda alimentar com parceria entre poder público e mundo associativo. É importante lembrar que associaçôes francesas foram protagonistas da mobilização que antecedeu à criação do programa em 1987 e, nisso, foram amplamente apoiadas pelo então presidente da Comissão Europeia, o francês Jacques Delors.

O número de pessoas beneficiadas com ajuda aumentou a cada ano no país devido tanto à situaçáo de carência de famílias, trabalhadores pobres e desempregados franceses quanto ao aumento de imigrantes pobres. No curto período de 2006 a 2010, o número de beneficiários aumentou em mais de um milhão de pessoas (CONSEIL NATIONAL DE L'ALIMENTATION, 2012, p. 21). Apesar disso, as associaçóes que recebem os alimentos relatam não conseguirem, por razóes financeiras, atender a toda a demanda.

Em 2014 o PEAD foi substituído pelo Fundo Europeu de Ajuda às pessoas necessitadas, FEAD com duração prevista até 2020. De acordo com o 
regulamento do fundo, cada país deverá cofinanciar no mínimo 15\% do custo do seu programa nacional (EUROPEAN COMMISSION, 2014).

As negociaçóes em torno à reforma do PEAD que levaram à criação do fundo são reveladoras de tensóes com relação a políticas comuns, a dilemas enfrentados nas decisóes e a formas de conciliar ou confrontar interesses transversais de grupos e setores dentro do bloco europeu. Em todo caso, programa e fundo evidenciam o reconhecimento oficial da existência do problema da insegurança alimentar e da necessidade de ajuda para uma parte significativa da população. Tais iniciativas públicas são resultado da mobilização de associaçóes e atores políticos e de pressóes feitas dentro da UE por governos de países que sofreriam maior impacto com a supressão dos recursos para a ajuda alimentar às pessoas carentes. O PEAD tinha caráter de exceçáo dentro da política agrícola comum e, inclusive, era visto como temporário. $\mathrm{O}$ atual FEAD é temporário e náo está integrado à política agrícola, mas sim ao Fundo Social Europeu. Apesar de que a UE propóe que o fundo náo se limite à distribuição de alimentos e seja utilizado para açóes gerais de luta contra a pobreza, os países continuam destinando os recursos integralmente à ajuda alimentar (BADIA et al., 2015).

Em complemento à apresentação que acabamos de realizar, é indispensável destacar que o programa de ajuda europeu consiste em subvençôes públicas de caráter assistencial. Estas não integram um combate à insegurança alimentar que efetivamente incorpore nas políticas sociais e econômicas o acesso da população pobre aos alimentos. Além disso, o formato da política não favorece a destinaçáo de recursos públicos para reforçar o tecido econômico e produtivo com compras públicas descentralizadas que deem oportunidades a produtores locais. Um grande volume de recursos públicos termina, pela via de licitaçóes centralizadas para compra de alimentos, favorecendo aos maiores produtores e empresas já que estes possuem melhores condiçóes para ganhar as licitações. Desse modo, estratégias e procedimentos operacionais escolhidos conectam a ajuda alimentar ao circuito econômico hegemônico, contrariando, na prática, a visão crítica das organizações sociais que pressionaram pelo envolvimento do poder público com o problema. 


\section{O funcionamento da ajuda alimentar na França}

Um traço comum nos países europeus com relação à ajuda alimentar é o envolvimento de associaçóes caritativas e de solidariedade. Uma auditoria realizada em 2009 pelo tribunal de contas europeu nos quatro países que naquele ano receberam mais recursos do PEAD (França, Itália, Espanha e Polônia) observou heterogeneidade, tanto entre países quanto dentro de cada um deles, com relaçáo à frequência, forma da distribuição, qualidade e quantidade dos produtos propostos. Além disso, chamou atenção para a dificuldade em estabelecer com precisão o número efetivo de beneficiários devido às diferenças no modo de contagem adotado pelas associaçóes. A avaliaçáo confirmou que pelo menos $80 \%$ das pessoas que trabalhavam nas associaçóes eram voluntárias (CONSEIL NATIONAL DE L'ALIMENTATION, 2012). Portanto, o trabalho dos cidadãos, dedicando seu tempo principalmente, é um dos principais recursos que permitia a existência desse programa público.

O papel desempenhado pelas associaçóes francesas no PEAD e no fundo que o sucedeu envolve um conjunto amplo de atividades, dentre as quais transporte dos produtos, armazenamento, gestáo de estoques, distribuição, tarefas administrativas de planejamento, elaboração de orçamentos e prestação de contas. Os procedimentos foram, ao longo do tempo, tornando-se mais complexos em razáo da dimensão da ajuda e das normas adotadas, passando a ser mais exigentes em capacidades de organização e gestão. Sendo as tarefas executadas majoritariamente por pessoas não remuneradas, as associaçóes precisaram ampliar sua base de voluntários e, ainda, apelar a pessoas com competências nas áreas de gestão, informática e controle, além de contratar funcionários para certas atividades (LE CROM; RETIÈRE, 2003). Visto que a contribuição da UE representa apenas uma parte dos alimentos que as associaçóes distribuem, cada entidade atua em uma série de outras frentes para garantir a ajuda, cada uma dessas com suas exigências específicas ${ }^{6}$.

6 Os recursos da UE representam em média I/3 dos recursos das principais associações de ajuda alimentar francesas (INSPECTION GEENÉRALE DES AFFAIRES SOCIALES, 2008). No caso do Restos du Coeur, porém, eles representaram somente 11,3\% do total em 2014. As demais fontes foram: financiamentos públicos $e$ subvenções: 18,6\%; doações diversas de pessoas e empresas: 44.9\%; venda de ingressos para concertos dos Enfoirés (artistas que apoiam a entidade); venta de CDs e DVDs: 12,5\%; outras fontes: 12,7\%. A isso se soma o trabalho dos voluntários (LES RESTAURANTS DU COEUR, 2014, p. 24). 
Quanto à institucionalidade, a organização da ajuda está a cargo do Ministério dos Assuntos Sociais e da Saúde e do Ministério da Agricultura, ao qual está subordinada à agência responsável por licitaçóes e compra dos alimentos, além do controle das associaçóes caritativas e de solidariedade. Ambos os ministérios são responsáveis pelo Programa Nacional de Ajuda Alimentar (PNAA), que complementa os recursos europeus e contribui com aquisição de frutas, legumes, carnes e peixes. Esse programa passou, também, a subvencionar projetos de acompanhamento dos beneficiários da ajuda e de modernização da logística das associaçóes. Ademais, deve-se mencionar que o poder público está presente no nível local por meio dos centros municipais e intermunicipais de ação social, vinculados a governos departamentais e locais, que têm autonomia para decidir como atuar na ajuda em cada cidade e relacionar-se com as iniciativas sociais ligadas ao tema.

A ajuda alimentar é, portanto, uma constelação que agrupa diferentes tipos de organizaçóes governamentais e não governamentais. Nos territórios, as iniciativas coexistem por vezes sem articulação ou coordenação nas açóes (BADIA et al., 2015). São quatro as principais associaçóes que recebem recursos da UE e sua complementação pelo governo. Para isso, devem demonstrar capacidade organizacional, logística e de distribuição e atuação junto aos demandantes de ajuda em quase todo o território nacional ${ }^{7}$. São elas: o Secours Populaire Français, a Fédération des Banques Alimentaires, a Croix-Rousse Française e Les Restaurants du Cour-Relais du Cœur (conhecida como Restos du Cœur). Porém, o universo da ajuda alimentar náo se resume a essas quatro associaçóes, pois há outras iniciativas que não estáo conectadas ao programa da UE e cuja existência constitui mais uma evidência da extensão desse tipo de ajuda no país ${ }^{8}$.

7 Apenas associações oficialmente reconhecidas como de utilidade pública de acordo com a lei francesa de associações (promulgada em 190I) podem receber recursos públicos e doações privadas, realizar coletas e recorrer a benefícios fiscais.

8 Muitas entidades com atuação local estão ligadas aos bancos de alimentos ou à Croix-Rouge Française, que Ihes repassam produtos da ajuda europeia. Outras formas de ajuda surgidas a partir do final dos anos 1990 possuem conexão com os centros sociais públicos, como as mercearias sociais e solidárias, cujo objetivo é permitir ao beneficiário ter liberdade de escolha em uma oferta de produtos. Ali, os alimentos são adquiridos, seja com bônus fornecidos por serviços sociais ou associações, seja com contribuição mínima do comprador (BADIA et al., 2015). 
Com o propósito de chamar a atenção para aspectos significativos das associaçóes, daremos destaque ao Restos du Cœur. A entidade foi fundada em 1985 por iniciativa de Michel Colucci (Coluche), ator de grande popularidade, que lançou, durante uma entrevista em uma emissora de rádio, a ideia de obter doaçóes que permitissem entregar uma refeição quente a cada pessoa necessitada durante o inverno (BOGGIO, 1992). A ideia e a intensa mobilização social que se seguiu à sua difusão, juntamente com a capacidade de Coluche em envolver a mídia, os atores políticos e, sobretudo, a população, levaram à fundação da associação. Trinta anos mais tarde, a rede "Restos du Coeur" já estava constituída pela associação nacional, 118 associaçóes departamentais e mais de dois 2 mil centros de distribuiçáo de alimentos e de inserção social onde atuam milhares de voluntários (Tabela 9.2). A capilaridade da associação no território e a quantidade de voluntários envolvidos são evidências de que insegurança alimentar e ajuda em alimentos geram importante mobilização social.

Tabela 2 - Restos du Coeur, 1985-2015

\begin{tabular}{lcc}
\hline & $\mathbf{1 9 8 5}$ & $\mathbf{2 0 1 5}$ \\
\hline Pessoas acolhidas & 70.000 & 950.000 \\
Refeições distribuídas & 8,5 milhões & 128,5 milhões \\
Voluntários & 5.000 & 69.200 \\
Centros & 100 & 2.111 \\
\hline
\end{tabular}

Fonte: Les Restaurants du Coeur, 2015.

A distribuição de alimentos é a principal ação e mobiliza a maior quantidade de recursos materiais e humanos, porém não é a única atividade da associação. São desenvolvidas outras ações de combate à pobreza, de promoção e reinserçáo social, tais como apoio escolar, acesso aos direitos e à justiça, bem como ateliês de formação profissional e, em algumas cidades, alojamentos sociais de urgência.

Após a morte de Coluche, em acidente ocorrido em junho de 1986, duas outras ideias lançadas por ele foram retomadas pelo poder público. Elas estão presentes nas bases atuais do sistema de ajuda alimentar. A primeira é a ideia de "abrir as geladeiras da Europa" ("ouvir les frigos de l'Europe"), isto é, 
entregar às associaçóes os estoques de intervenção europeus que, até então, eram armazenados com elevado custo para a Comissáo Europeia e destruídos posteriormente (PARLEMENT EUROPEEN, s.d.). Como mostramos, o PEAD consistiu na liberação dos estoques para uso por associaçóes que atuam junto a famílias e pessoas pobres. Coluche e o Restos du Coeur, com os apoios que mobilizaram, foram protagonistas na criação do PEAD.

A segunda ideia de Coluche retomada pelo poder público consistiu em conceder incentivos fiscais às pessoas físicas que fizessem doaçóes financeiras às associaçóes de ajuda alimentar. A inquietação de Coluche era especialmente com a inexistência de deduçóes para os doadores de menores recursos, que eram os principais contribuintes das associaçóes. Isso deu lugar a uma emenda na lei de orçamentos francesa que estabeleceu as regras dessas deduçóes fiscais.

A entrega de ajuda alimentar pelas entidades ocorre de diversas formas. A mais frequente é a distribuição de cesta de alimentos, preparada pela associação ou pelo próprio beneficiário no centro de distribuição sob a supervisão dos voluntários, com produtos para refeiçóes de uma ou duas semanas. Outro tipo consiste em refeiçôes quentes (almoço em centros de distribuição diurnos, café da manhã ou refeiçôes nos caminhóes à noite em lugar fixo). Também há a distribuição de refeição, sanduíche ou sopa, por algumas entidades, em rondas noturnas nas ruas. Outra variação são as mercearias sociais ou solidárias, que atendem a pessoas e famílias cadastradas. Uma associação pode adotar mais de uma forma de atuação. Uma ajuda específica em produtos de alimentação para bebês é realizada em alguns centros do Restos du Coeur (CONSEIL NATIONAL DE L'ALIMENTATION, 2012).

As associaçóes são objeto de diversos tipos de controle pelo poder público com relação a aspectos sanitários e normas de higiene no armazenamento, transporte, preparo e distribuiçáo dos alimentos, bem como quanto à gestão dos recursos recebidos. Além disso, com frequência são realizados levantamentos e estudos, patrocinados por instituiçóes governamentais ou náo governamentais, sobre qualidade dos alimentos, composição nutricional das cestas ou das refeições distribuídas, satisfação dos beneficiários, e outros aspectos.

As estimativas quanto ao número de beneficiários potenciais da ajuda na França não são conclusivas. Sabe-se que quase 4 milhóes de pessoas são atendidas pelas principais associaçóes (OBSERVATOIRE DES INÉGALITÉS, 
2015 , p. 33). No entanto, há indivíduos isolados e famílias que não procuram a ajuda devido à distância dos centros de distribuição ou por medo à desqualificação social. São consideradas ainda como potenciais beneficiárias aquelas pessoas cuja alimentaçáo é limitada em quantidade e deficiente em nutrientes, porém não preenchem os requisitos para receber a ajuda. Para atender a exigências da UE e em face da demanda que reiteram ser crescente as associaçóes buscam comprovar que os beneficiários são os mais necessitados. Elas realizam focalização, baseada em inscriçáo prévia e exame de rendimentos e despesas, calculando "o que sobra para viver" ao aplicar o critério de recursos e número de pessoas no domicílio. Há associações que estabelecem parâmetro próprio para avaliação anual das pessoas inscritas.

Existe estreita conexão entre insuficiência de renda (por falta de trabalho ou baixas remuneraçôes), precárias condições de habitação e busca de ajuda para se alimentar (OBSERVATOIRE DES INÉGALITÉS, 2015). Diversas estimativas mostram aumento da pobreza crônica durante a última década (OBSERVATOIRE NATIONAL DE LA PAUVRETÉ ET DE L'EXCLUSIONSOCIALE, 2015). Dados divulgados pelas associaçóes apresentam outros aspectos do perfil da populaçáo que se beneficia da ajuda, permitindo conhecer mais do que seu nível de renda. Em 2013, o Secours Catholique relatou que mais da metade das pessoas atendidas recebiam benefícios sociais entregues pelo poder público (renda mínima de inserção ou renda de solidariedade ativa) enquanto que $16 \%$ náo recebiam nenhum benefício. Dentre as pessoas ajudadas, $38 \%$ estavam ativas no mercado de trabalho, sendo que $15 \%$ tinham um emprego (OBSERVATOIRE NATIONAL DE LA PAUVRETÉ ET DE L'EXCLUSION SOCIALE, 2015, p. 21). Outra associação, o Secours Populaire Français, apontou que metade dos ajudados recebia do governo a renda de solidariedade ativa, demonstrando "[...] que este benefício náo permite autonomia financeira suficiente para dispensar procurar ajuda suplementar junto à rede de caridade" (OBSERVATOIRE NATIONAL DE LA PAUVRETÉ ET DE L'EXCLUSION SOCIALE, 2015, p. 21). Além disso, foi constatado que $17 \%$ dos beneficiários têm salário, situação reveladora de que "[...] a participaçáo no mercado de trabalho é marcada por condiçóes particularmente pouco favoráveis: salários muito baixos, pouca duração do emprego e do trabalho expóem as famílias à grave insuficiência de recursos que os leva a recorrer às ajudas caritativas suplementares" (OBSERVATOIRE 


\section{NATIONAL DE LA PAUVRETÉ ET DE L'EXCLUSION SOCIALE, 2015,} p. 21). Finalmente, é relevante apontar que uma pesquisa realizada em 2012 para a federação de bancos de alimentos constatou que, apesar da presença de número importante de imigrantes, as pessoas de nacionalidade francesa representavam a maior proporção entre os assistidos (IPSOS, 2012).

Outros elementos importantes do perfil dos beneficiários da ajuda alimentar foram fornecidos por pesquisa realizada no inverno 2011-2012 com amostra aleatória de usuários de grandes centros de distribuiçáo localizados em seis territórios no país ${ }^{9}$. Foi demonstrado que a metade da populaçáo que frequenta as estruturas recorria à ajuda há mais de dois anos. Comparativamente a estudo similar, realizado nos mesmos lugares em 2004-2005, foi constatado o aumento do número de desempregados, aposentados e pessoas com emprego (GRANGE et al., 2013).

Além da presença dos poderes públicos e das organizações sociais, é preciso mencionar ainda a implicação de atores econômicos na ajuda alimentar. Dentre eles, encontram-se: a) empresas que participam como fornecedores de produtos adquiridos pelo governo, após licitaçôes, com recursos da UE e nacionais, ou de produtos adquiridos pelas associaçóes de ajuda com recursos obtidos junto à sociedade; b) produtores de alimentos (agricultores e cooperativas) que fazem doaçóes às associaçóes; c) empresas da indústria agroalimentícia que, por diversas razóes, inclusive dar vazão à superprodução, fazem doaçôes às associaçôes; d) supermercados que fazem doaçôes de produtos não vendidos, mas dentro do prazo de validade para consumo; e) supermercados que permitem às associaçóes realizar, de modo programado, coletas de doaçóes junto aos clientes.

Doaçóes de empresas e pessoas físicas representam parte substantiva dos recursos de associaçóes de ajuda alimentar e são determinantes para a manutenção de sua atividade. Elas são estimuladas pela existência de dispositivos fiscais, como assinalamos. A regulamentação sobre cada tipo de doação é estrita e seu cumprimento submetido a controle constante pelos órgãos públicos. Um levantamento do tribunal de contas francês calculou, em 2008, o custo

9 Paris, Marseille, Grand-Dijon, Seine-Saint-Denis, Val-de-Marne et Hauts de Seine. A pesquisa "Alimentation et état nutritionnel des bénéficiaires de l'ai de alimentaire" (Étude Abena) foi realizada para o Ministério da Saúde e comparada aos dados coletados no inverno 2004-2005, na primeira versão do estudo. 
fiscal das doações de pessoas físicas em favor das quatro associaçóes atuantes na distribuição de alimentos que recebem fundos da UE. Naquele ano, por exemplo, o Restos du Coeur, que recebeu o maior volume de doaçóes, obteve o total de 34,5 milhões de euros (INSPECTION GÉNÉRALE DES AFFAIRES SOCIALES, 2014, p. 67).

O modelo francês de ajuda alimentar apoia-se explicitamente na parceria público-privado e no grande envolvimento da sociedade por meio de doaçóes em dinheiro, produtos e trabalho voluntário. Os recursos destinados anualmente no país à ajuda representam, pelo menos, um bilhão de euros, caso as contribuiçóes da UE e dos orçamentos nacionais, as doaçóes financeiras e em produtos, e o valor monetário correspondente ao tempo de trabalho das pessoas voluntárias nas associaçôes sejam somados (COUR DES COMPTES, 2009, p. 44). O tribunal de contas calculou que o tempo entregue pelos 120.000 voluntários ao serviço da ajuda alimentar representou em 2009 aproximadamente 546 milhóes de euros (COUR DES COMPTES, 2009, p. 44) ${ }^{10}$.

A França não possui uma política de segurança alimentar que tome em conta todos os aspectos da questáo e que forneça respostas sustentáveis para a solução do problema da insegurança. A ajuda alimentar para as pessoas carentes é considerada no país como "de urgência" e funciona como socorro frente a uma situação imediata. Em contraposição, existe uma situaçáo perene de insegurança, comprovada pelo fato departe dos beneficiários ser dependente da ajuda há muitos anos e por haver continuamente trabalhadores e pessoas aposentadas que procuram a ajuda pela primeira vez. Em geral as pessoas procuram as associaçóes - ou são diretamente encaminhadas a elas pelos serviços sociais públicos - porque não encontram respostas de política públicas aos seus problemas ou essas são insuficientes.

A ajuda alimentar, envolvendo grande quantidade de atores e de recursos públicos e privados, é uma resposta precária a situaçóes que não são tratadas

10 A partir do número de voluntários das associações nacionais, que executam no mínimo meia jornada de atividades por semana, foi calculado o total de horas de trabalho anual. Considerando esse total e a hipótese de que a ajuda fosse gerida diretamente no poder público por funcionários remunerados com salários praticados no país, chegou-se à cifra de 546 milhões de euros. Tal montante corresponderia à economia dos cofres públicos com o trabalho voluntário (COUR DES COMPTES, 2009, p. 47). Uma intervenção direta do poder público exigiria que ele destinasse à ajuda em alimentos um valor ao menos cinco vezes maior (CONSEIL NATIONAL DE L'ALIMENTATION, 20I2, p. 69). 
ou resolvidas pelos sistemas sociais. No caso da França, o sistema social e os benefícios sociais distribuídos não resolvem esse tipo de necessidade, e nem incidem suficientemente sobre as causas que levam a cada ano, nesse país com alta produtividade agrícola e famoso por sua gastronomia -, milhóes de pessoas a buscarem ajuda para se alimentar. As dificuldades das famílias em ter um orçamento suficiente para as necessidades alimentares estáo relacionadas a questóes estruturais, aos baixos salários, ao desemprego ou à necessidade de destinar alta proporção dos seus recursos financeiros para habitaçáo. Diante desse problema crônico, as açóes não têm um enquadramento consistente de política pública, os dispositivos de financiamento são provisórios e não se visualiza uma resposta com horizonte de médio ou longo prazo. A ajuda alimentar continua sendo principalmente realizada por associaçóes, cuja mobilização, devemos destacar, revela importante reação social frente à penúria em que vivem outras pessoas.

O formato da ajuda na França inclui, como vimos, a participação estatal e de atores econômicos, porém a base principal é fornecida pelas organizaçóes sociais. $\mathrm{O}$ protagonismo dessas associaçóes não impede que a ajuda alimentar seja objeto de críticas por parte das próprias pessoas engajadas, de outros setores da sociedade e de atores políticos. Existem críticos à ajuda em alimentos que a consideram geradora de estigma para as pessoas obrigadas a recorrer recorrerem a associaçóes caritativas para ter direito à alimentação. Outros críticos afirmam que ela é mantida em níveis mínimos para que náo se torne atraente para os pobres aptos para o trabalho. Para outros, a ajuda provoca passividade e dependência (AMISTANI; TERROLLE, 2008; CLEMENT, 2001). Outro ponto de vista aponta para o fato da operacionalização do modelo francês de ajuda priorizar abastecer-se principalmente com compras públicas de alimentos no sistema agroindustrial e na grande distribuição, em lugar de estar conectada aos agricultores e recursos produtivos dos territórios, o que contribuiria para dinamizar a economia local e regional e aproximar produtores e consumidores (PATUREL; BLANCHOT, 2014).

\section{Considerações finais}

Para finalizar, problematizaremos a conexão entre acesso à alimentação e inclusão social e, em seguida, os limites da ajuda em alimentos em termos de mobilização da sociedade e de política pública no atual contexto europeu. 
O problema do acesso à alimentação nos países desenvolvidos não tem a dramaticidade do que ocorre em países pobres, onde há por vezes situaçôes em estado físico degradado ou morrendo de fome. Porém, a imagem do mendigo que vive isolado e nas ruas náo corresponde, na realidade atual de países da Europa, ao perfil típico de quem busca ajuda para se alimentar. As informaçóes apresentadas nesse artigo apontam, ao contrário, para a realidade complexa da pobreza, situaçáo na qual vivem pessoas com características diversificadas. Nesses países normalmente não há pessoas expostas no espaço público que morrem de fome, mas há gente com déficit alimentar em número de calorias e de nutrientes. Há pessoas que não fazem diariamente todas as refeiçóes necessárias. Há insegurança por razóes financeiras. Há desequilíbrios alimentares na populaçáo pobre pela falta de nutrientes proporcionados por frutas, legumes, carnes e peixes, e pelo excesso de alimentos com açucares e massas que leva a sobrepeso, obesidade e risco de doenças crônicas.

Uma parcela da população enfrenta restrições sociais por estar excluída do mercado de alimentos e necessitar recorrer à ajuda pública. Um dos efeitos sociais disso é o estigma que resulta de comparecer aos locais de doação de alimentos. A não satisfação das necessidades elementares repercute negativamente sobre a liberdade, a dignidade, respeito de si mesmo e a participaçáo dos indivíduos na vida social. A impossibilidade de acesso à alimentação pelos seus próprios recursos faz com que as pessoas tenham uma vida familiar mais pobre em compartilhamento, assim como uma vida social empobrecida de interaçóes e sociabilidade. A comida, vital para o bem-estar físico, é também ingrediente essencial da relaçáo com os outros, da convivência, da dignidade, da autoestima e do reconhecimento. A comensalidade tem importantes dimensões culturais e sociais. A forma como as refeiçóes são preparadas, consumidas e compartilhadas expressam características fundamentais das relaçóes sociais (MONTANARI, 2013). Quando, por razões materiais se restringe na vida cotidiana a possibilidade de alimentar-se, existe o risco de marginalizaçáo e exclusão social (CESAR, 2006, 2008), o qual se torna mais agudo em uma sociedade rica, como é o caso da maioria dos países europeus.

As informaçóes relativas à pobreza, insegurança alimentar e ajuda em alimentos, apresentadas neste artigo sobre a Europa e com mais detalhe sobre a França, são reveladoras da decomposição das proteções coletivas do Estado 
social. As fissuras nos sistemas de proteção e bem-estar, que provocam a exclusão de uma parcela da população em relação aos direitos sociais, não são novas e não cessaram de expandir nas últimas décadas. Tais fissuras se apresentam em dimensóes e componentes diferentes em cada país, contudo, elas são em praticamente todo o continente provocadas por desregulaçáo e competitividade econômicas, transformaçóes no mundo do trabalho e redução da presença do Estado no campo social.

Nesse contexto, ocorreu a expansão da assistência social como forma de enfrentamento da pobreza (DUVOUX, 2013). Não se trata apenas do ressurgimento da assistência pública dentro do conjunto das políticas sociais, mas também da expansão de iniciativas a cargo da própria sociedade que, na ausência ou escassa presença do Estado, se mobiliza para prestar socorro, ajudar, promover solidariedade e vínculos sociais.

$\mathrm{O}$ artigo demonstrou que a ajuda alimentar apoiada com recursos do bloco europeu é vista como complemento das políticas nacionais e das açóes privadas executadas com o trabalho de voluntários. A ajuda mobiliza grande quantidade de atores e de recursos públicos e privados, porém, é uma resposta precária a situaçóes que não são tomadas em conta pelos sistemas de proteçấo social ou, quando o sáo, permanecem não resolvidas. $\mathrm{O}$ programa e o fundo europeus não fazem parte de um combate à insegurança alimentar que incorpore consistentemente nas políticas públicas o acesso da populaçáo pobre aos alimentos. O problema é tratado pelo ângulo da gestão humanitária mais do que pelo ângulo de direitos. Não são avançadas açóes para atacar as causas da insegurança no direito à alimentação, as quais estão relacionadas a questóes estruturais ligadas aos baixos salários, ao desemprego persistente ou à necessidade das famílias de destinar alta proporção dos seus recursos financeiros para moradia.

A ajuda em alimentos aqui analisada é, ademais, expressiva de novos modos de colocar em prática no campo da política pública o controverso e multifacetado princípio da subsidiariedade. $\mathrm{O}$ exame do caso do PEAD permitiu apontar conflitos de visóes sobre as competências da UE, a autonomia dos estados membros quanto às decisóes em política social e a relação subsidiária da União com os estados membros.

Soma-se a isto a disputa pela destinação dos recursos do bloco de países e o debate permanente sobre quais seriam as fronteiras entre as políticas 
econômicas e as políticas sociais. Na visão de Barbier (2013), a construção econômica do grande mercado europeu contagia os domínios sociais, principalmente com a promoção da livre concorrência e do princípio das liberdades econômicas, que são hostis às "subvençôes" e aos serviços públicas. O resultado é a marginalização do social em proveito do econômico.

\section{Referências}

AMISTANI, C.; TERROLLE, DAMISTANI, C.; Terrolle, D. L'alimentation des sans-abri. Entre autonomie et dépendance. Anthropologie of food, 6, Manger pour vivre, [s. p.], sept. 2008. Disponível em: <http://aof.revues.org/4952>. Acesso em: 21 set. 2015.

ANTUOFERMO, M.; DI MEGLIO, E. Population and social conditions. Eurostat: Statistics in focus, v. 9, p. 1-8, 2012. Disponível em: <http://ec.europa.eu/eurostat/ documents/3433488/5584436/KS-SF-12-009-EN.PDF/85506ae5-6fc7-4eb1-bfda0b74c5b5b1b2>. Acesso em: 17 nov. 2015.

BADIA, B. et al. Inégalites sociales et alimentation: rapport final. Fors Recherche sociale. Déc. 2014. Disponível em: <http://agriculture.gouv.fr/ministere/inegalites-sociales-etalimentation>. Acesso em: 3 nov. 2015.

BANQUES ALIMENTAIRES, RESTOS DU CEUR, CROIX-ROUGE FRANÇAISE, SECOURS POPULAIRES FRANÇAIS. Les associations francaises poursuivent leur mobilisation pour maintenir l'aide alimentaire européenne [s. d]. Disponível em: <http://www.restosducoeur.org/sites/default/files/Dossier\%20de\%20presse\%20Airfood\%20 Project\%20-\%20Sauver\%20l'aide\%20alimentaire\%20europ\%C3\%A9enne\%20151012. pdf>. Acesso em: 26 set. 2015.

BARBIER, J-C. “ Modèle social européen” et "gouvernance européenne”. Informations sociales, n. $175,2013 / 1$, p. 26-32, 2013. Disponível em: <https://www.cairn.info/revueinformations-sociales-2013-1-page-26.htm>. Acesso em: 17 nov. /11/2015.

BOGGIO, P. Coluche. Paris: Éditions J’ai lu, 1992.

CASTEL, R. As metamorfoses da questão social: uma crônica do salário. Petrópolis, RJ: Vozes, 1998.

CESAR, C. Les usages de l'aide alimentaire à la lumière des liens sociaux : un aspect du volet socio-anthropologique de l'étude Abena. Bulletin épidémiologique hebdomadaire, n. $11-12$, p. $83-84,2006$, p. $83-84$. 
Dépendre de la distribution d'aide alimentaire caritative. Le cas des sans-papiers. Anthropology of Food, n. 6, Manger pour vivre, 2008. Disponível em: <https://aof.revues. org/507>. Acesso em: 21 set. 2015.

CHAMBON, N. Subsidiarité contre solidarité ? L'exemple du programme européen d'aide aux plus démunis. Les Brefs, n. 30, p. 1-4, oct. 2011. Disponivel em: <http://www.institutdelors. eu/media/bref30-nchambon-pead-fr_01.pdf?pdf=ok>. Acesso em: 17 nov. 2015.

CLEMENT, A. De l'évergétisme antique aux Restos du coeur: Etat et associations dans l'histoire du secours alimentaire, Revue internationale d'économie sociale, v. 279, 2001, p. 26- 43, 2001.

Faut-il nourrir les pauvres? Une perspective historique. Anthropologie of food, v. 6, p. 1-15, Sept. 2008. Disponível em: <http://aof.revues.org/4283>. Acesso em: 21 set. 2015.

CONSEIL NATIONAL DE L'ALIMENTATION. Aide alimentaire et accès à l'alimentation des populations démunies en France, Avis avis n. 72, 22 mar. 2012. Disponível em: <http:// www.cna-alimentation.fr/wp-content/uploads/2013/04/cna_avis72.pdf> Acesso em: 17 nov. 2015.

COUR DES COMPTES. Communication d'un rapport sur les circuits et mécanismes financiers concourant à l'aide alimentaire en France. Sept. 2009. Disponível em: <http:// www.assemblee-nationale.fr/commissions/cfin-enquete-CC-aide-alimentaire.pdf $>$. Acesso em: 21 out. 2015.

DARMON, N. et al. L'insécurité alimentaire pour raisons financières en France. La lettre de l'Observatoire National de la Pauvreté et de l'Exclusion sociale, n. 4, p. 1-21, juin. 2010.

DELAVIGNE, A-E.; MONTAIGNE, K. De la honte d'avoir faim dans un pays riche. Introductionn: "manger pour vivre: l'alimentation en condition de précarité dans les pays "riches". Anthropologie of food, 6, Manger pour vivre, 2008. Disponível em: <http://aof. revues.org/4243>. Acesso em: 21 set. 2015.

DUVOUX, N. Comment l'assistance chasse l'État social. Idées économiques et sociales, n. 171, 2013/1, p. 10-17, 2013. Disponível em: <http://www.cairn.info/revue-ideeseconomiques-et-sociales-2013-1-page-10.htm>. Acesso em: 17 out. 2015.

EUROPEAN COMMISSION. Fund for European Aid to the Most Deprived (FEAD). Disponível em: <http://ec.europa.eu/social/main.jsp?langId=en\&catId=1089>. Acesso em: 17 nov. 2015. 
Free food for the most deprived persons in the EU (Archive), [s. d.]. Disponível em: <http://ec.europa.eu/agriculture/most-deprived-persons/archive_en.htm>. Acesso em: 17 nov. 2015.

Press Release Database. Memo, 25 fev. 2014. Disponível em: <http://europa.eu/ rapid/press-release_MEMO-14-131_en.htm>. Acesso em: 17 nov. 2015.

FAO, FOOD AND AGRICULTURE ORGANIZATION OF THE UNITED NATIONS - FAO. Declaração de Roma Sobre a Segurança Alimentar Mundial e Plano de Acção da Cimeira Mundial da Alimentação. 1996. Disponível em: <http://www.fao.org/docrep/003/ w3613p/w3613p00.HTM>. Acesso em: 17 out. 2015.

The State of Food Insecurity in the World (SOFI) 2014. Roma, 2014. Disponível em: <http://www.fao.org/publications/card/en/c/56efd1a2-0f6e-4185-8005-62170e9b27bb/>. Acesso em: 17 out. 2015.

GAROT, G. Lutte contre le gaspillage alimentaire: propositions pour une politique publique. Rapportau Premier Ministre. 2014. Disponível em: <http://www.developpementdurable.gouv.fr./IMG/pdf/Rapport-Gaspillage-alimentaire_cle0ea927.pdf>. Acesso em: 17 nov. 2015.

GRANGE, D. et al. Alimentation et état nutritionnel des bénéficiaires de l'aide alimentaire: Etude Abena 2011-2012 et évolutions depuis 2004-2005. ORS, InVS, INPES, Ministère des Affaires Sociales et de la Santé, 2013. Disponível em: <http:/www.inpes.sante.fr/etudes/ pdf/2013-abena2-rapport.pdf>. Acesso em: 17 nov. 2015.

HIGH Level Panel of Experts on Food Security and Nutrition of the Committee on World Food Security. Food losses and waste in the context of sustainable food systems. HLPE Report 8, 2014. Rome, 2014. Disponível em: <http://www.fao.org/3/a-i3901e.pdf>. Acesso em: 17 out. 2015 .

INSPECTION GENERALE DES AFFAIRES SOCIALES. Conseil général de l'agriculture, de l'alimentation et des espaces ruraux. Evaluation du programme Européen d'Aide aux plus démunis et de l'organisation de l'aide alimentaire française. Rapport définitif, juil. 2008.

Conseil général de l'alimentation, de l'agriculture et des espaces ruraux. Évaluation ex-ante du Programme Opérationnel 2014-2020 pour la mise en œuvre du Fonds européen d'aide aux plus démunis (FEAD). Rapport, mars. 2014.

IPSOS. Etude nationale sur le profil des bénéficiaires d'une aide alimentaire auprès des associations et C.C.A.S. partenaires. 2012. Disponível em: <http://www.banquealimentaire. 
org/sites/default/files/rapport_ipsos_ffba_volet_beneficiaires_media.pdf>. Acesso em: 17 out. 2015.

JONET, I. Dans la riche Europe, il y a encore des gens qui ont faim. Disponível em: <http://www.banquealimentaire.org/sites/default/files/article_-_droit_a_lalimentation _-_2012_06_26.pdf>. Acesso em: 16 out. 2015.

LE CROM, J-P.; RETIERE, J-N. Nourrir les pauvres : assister et/ou entreprendre? In: PROUTEAU, L. (sous la direction de). Les associations entre bénévolat et logique d'entreprise. Rennes, Presses universitaires de Rennes, 2003, pp. 67-84.

LEGROS, M. Nouveaux paysages de lutte contre la pauvreté: l'impact de la crise économique. Quatrièmes Rencontres Nationales des Epiceries Solidaires, [s. d.]. Disponível em: <http://www.epiceries-solidaires.org/files/Intervention_Michel_Legros.pdf>. Acesso em: 21 out. 2015.

LES RESTAURANTS DU COEUR. Rapport annuel 2013-2014. Brochure. 2014.

LES RESTAURANTS DU COEUR. 30 ans de solidarité... Disponível em: <http://www. restosducoeur.org/content/30-ans-de-solidarit\%C3\%A9\%E2\%80\%A6>. Acesso em: 28 set. 2015.

MONTAGUT, X.; GASCÓN, J. Alimentos desperdiciados: un análisis del derroche alimentario desde la soberanía alimentaria. Barcelona; Quito: Icaria; Instituto de Altos Estudios Nacionales; Xarxa de Consum Solidari, 2014.

MONTANARI, M. Comida como cultura. São Paulo: Senac São Paulo, 2013.

OBSERVATOIRE DES INEGALITES. Rapport sur les inégalités en France 2015. 4 juin 2015. Disponível em: <http://www.inegalites.fr/spip.php?page=analyse\&id_ article=2064\&id_groupe=9\&id_rubrique=28\&id_mot=30>. Acesso em 17 out. 2015 .

OBSERVATOIRE NATIONAL DE LA PAUVRETE ET DE L'EXCLUSION SOCIALE. Lévolution de la pauvreté en France: les nouvelles formes de l'aggravation. Suivi annuel des indicateurs de pauvreté et d'exclusion social. Édition 2015. Disponível em: <https://www. onpes.gouv.fr/IMG/pdf/Rapport_Indicateurs-2015-2.pdf>. Acesso em: 17 out. 2015.

PARLAMENTO EUROPEU. Regulamento (UE) n. o 223/2014 do parlamento europeu e do conselho de 11 de março de 2014 relativo ao Fundo de Auxílio Europeu às Pessoas mais Carenciadas. Jornal Oficial da Uniáo Europeia, p. 72-81, 12 mar. 2014. Disponível em: <http://eur-lex.europa.eu/legal-content/PT/TXT/PDF/?uri=CELEX:32014R0223\&from= ES>. Acesso em: 28 set. 2015. 
PARLEMENT EUROPEEN. 50 ans de Parlement europeen en video. Coluche veut distribuer aux pauvres des excedents alimentaires. [s. d]. Disponível em: <http://www. europarl.europa.eu/resources/library/media/20080319MLT24658/20080319MLT24658. wmv>. Acesso em: 15 maio 2015.

PATUREL, D.; BLANCHOT, V. L'aide alimentaire. En bout de courses ? Histoire de... Conférence-débat. 26 mars. 2014. Mission Agrobiosciences. Toulouse. Disponível em: <http://www.agrobiosciences.org/IMG/pdf/Cahier_Aide_alimentaire_DEF.pdf>. Acesso em: 17 nov. 2015.

POLANYI, K. A Grande Transformação: as origens de nossa época. Rio de Janeiro:, Editora Campus Ltda, 1980.

SASSIER, P. Du bon usage des pauvres. Paris: Fayard, 1990.

ZIEGLER, J. Destruição em massa: geopolítica da fome. São Paulo: Cortez, 2013.

\title{
Food Insecurity, Wastage and Food Aid in Twenty-Century Europe
}

\begin{abstract}
The article addresses sociological and political aspects of food insecurity and the food aid intended for millions of people in Europe. First is addressed the situation of food insecurity caused by poverty. Then, it is mentioned that the serious problem of wastage of food, which requires more attention of governments, international agencies and society, cannot be currently regarded as the cause of food insecurity. Finally is analyzed the main European food aid program and its performance in France.
\end{abstract}

Keywords: Food security. Poverty. Food aid. Wastage. Public policy.

Recebido em: 04/01/2016 Aceito em: 16/11/2016 